\title{
ÁREAS DEGRADADAS E CONTAMINADAS \\ ESTIMATIVA DE PERDA DE SOLO EM ÁREAS INCENDIADAS: O CASO DA BACIA HIDROGRÁFICA DO CÓRREGO TAQUARI NO DISTRITO FEDERAL
}

Eliakim Lemos Vasconcelos* - eliakimlemos@ gmail.com

Universidade Católica de Brasília

Thales Thiago Sousa Silva - thalesthiagoengenharia@gmail.com

Universidade Católica de Brasília

Getúlio Ezequiel Peixoto da Costa Filho - getuliop@ ucb.br

Universidade Católica de Brasília

Lucas Matheus Sousa Silva - lucasmss98@gmail.com

Universidade Católica de Brasília

Resumo: As erosões são um dos principais problemas ambientais da atualidade e colabora com a degradação dos solos. Os incêndios florestais têm a capacidade de potencializar os processos erosivos que ocorrem nas vertentes das bacias hidrográfias. Este trabalho tem como objetivo estimar as perdas de solo nas áreas incendiadas na bacia do Rio Taquari, Distrito Federal, utilizando a Universal Soil Loss Equation - USLE juntamente com técnicas de Sistemas de Informações Geográficas - SIG. Os resultados do fator de erosividade (R) variaram entre 8.510 e $8.571,63 \mathrm{MJ} . \mathrm{mm} / \mathrm{ha} / \mathrm{h}$. Os valores de erodibilidade $(\mathrm{K})$ variaram entre 0,018 e 0,039 t.ha.h $/ \mathrm{ha} / \mathrm{MJ} / \mathrm{mm}$. Para o fator topográfico (LS), foram encontrados valores entre 0,0039 e 50,55. O fator de uso do solo (C) foi adotado como 0,140 para o cenário 1 e 0,5 para o cenário 2. $\mathrm{O}$ fator de medidas conservacionistas do solo $(\mathrm{P})$ foi adotado como 1 . $\mathrm{O}$ estudo mostrou que a ocorrência de eventos de queimada na bacia do Rio Taquari implicou em maior estimativa de perda de solo. No cenário 1, as perdas ficaram entre os valores de 0,27 e 884,70 t(ha-ano) ${ }^{-1}$. Já no cenário 2 , as perdas ficaram entre os valores de 0,97 e 3159 $\mathrm{t}(\text { ha·ano })^{-1}$. A estimativa de perda de solo para o cenário 2 aumentou em $257 \%$ dos valores do cenário 1. Conclui-se que as áreas incendiadas na bacia do Rio Taquari resultaram em maior potencial erosivo, uma vez que o fator $\mathrm{C}$ tem fundamental importância na proteção dos solos contra esses processos.

Palavras-chave: Áreas incendiadas; Erosão hídrica; SIG. 

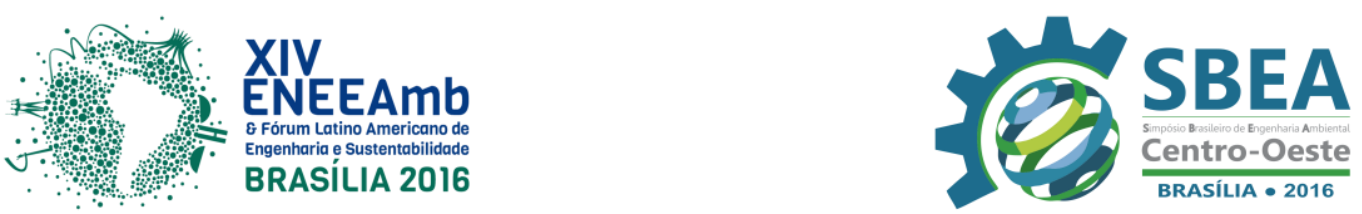

\section{INTRODUÇÃO E OBJETIVOS}

A erosão causada por fatores antrópicos é um problema mundial. Grandes áreas estão sujeitas à degradação do solo, às vezes de forma irreversível, por processos como a erosão. No Brasil, a principal forma de degradação ocorre em decorrência de perdas das camadas superficiais do solo. Segundo Hernani et al (2002), 750 milhões de toneladas de solo são perdidos por ano em áreas agrícolas e 70 milhões de toneladas para áreas de pastagem, em média.

Erosão é o processo de desagregação, transporte e deposição de partículas de solo. Acontece de forma natural, mas tem sido cada vez mais agravado por ação antrópica (Corrêa 2009). Com a retirada da cobertura vegetal nativa, os solos ficam desprotegidos e sujeitos a diversos tipos de intempéries.

Um fator importante quando se trata de erosão é o incêndio florestal. Conforme Lourenço (1988), os incêndios florestais deixam o solo exposto após destruírem a vegetação, favorecendo os processos de mobilização do solo. A falta de vegetação permite o contato direto das gotas das chuvas com o solo, aumentando os efeitos do "splash" e da ação erosiva da chuva. Esse processo acarreta a compactação do solo, o que resulta no desencadeamento do processo erosivo. Segundo o mesmo autor, além disso, a inexistência de vegetação reduz as taxas de infiltração e acresce o coeficiente de escoamento superficial, acarretando em uma maior quantidade de água que tem potencial para provocar os processos erosivos.

A ocorrência de incêndios florestais é uma das problemáticas ambientais mais sérias e relevantes nas Áreas de Proteção de Mananciais, pois causa perda de cobertura vegetal do solo, intensificação de processos erosivos, assoreamento das calhas dos corpos hídricos e o aumento na turbidez da água captada, incidindo negativamente na quantidade e qualidade da água captada para abastecimento da população (CAESB, 2012).

Poucos dados de campo estabelecem a relação entre os processos erosivos e incêndios florestais. Entretanto, a disseminação de conhecimento nessa área é de suma importância para compreensão dos processos pós-incêndio para avaliar os riscos associados a esses eventos. Assim, este estudo tem como objetivo estimar as perdas de solo nas áreas incendiadas na bacia do Rio Taquari utilizando a USLE juntamente com o Sistema de Informações Geográficas.

\section{MATERIAL E MÉTODOS}

\section{1. Área de estudo}

A sub-bacia hidrográfica do Rio Taquari está situada no Distrito Federal e inserida na Bacia Hidrográfica Lago Paranoá. No contexto de proteção ambiental, está inserida na Área de Proteção Ambiental do Planalto Central e na Área de Proteção Ambiental do Lago Paranoá, recebe titulação de Área de Proteção de Mananciais, estabelecida pelo Plano de Ordenamento Territorial do Distrito Federal - PDOT e é utilizada para abastecimento público. Abrange uma área de 5,57 km², com cota máxima de 1187 metros e mínima de 1035 metros. Apresenta vegetação de Cerrado e as classes de solos encontradas na região são Cambissolo, Latossolo Vermelho Amarelo e Latossolo Vermelho Escuro (EMBRAPA, 1978), com relevo que inclui áreas de rebordo e áreas de chapada elevada (ZEE, 2012). Possui, em sua maior porção, declividade entre 0,009 e $11 \%$, e nas áreas mais próximas ao córrego, os valores ficam entre 12 e $89,9 \%$. 

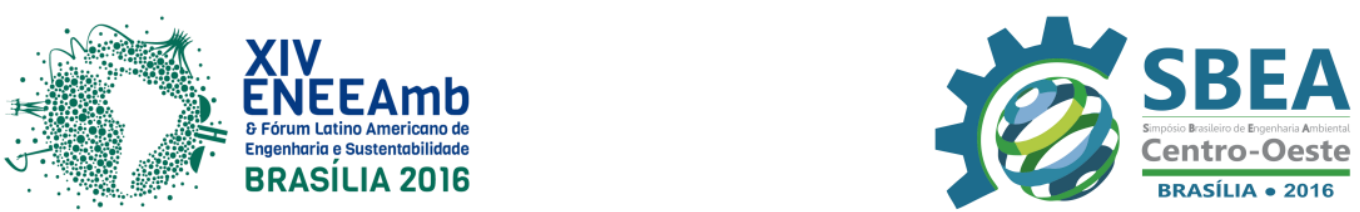

\subsection{Cenários}

Consideraram-se dois cenários distintos da mesma área para comparação dos valores de perda de solo. O primeiro cenário diz respeito à área antes dos eventos de queimada, onde a vegetação predominante é de cerrado; o cenário 2, após os eventos de queimada. Com exceção do fator de cobertura de solo (C), os fatores integrantes da USLE permanecem os mesmos para o cenário 1 e para o cenário 2 .

\subsection{Mapeamento das áreas incendiadas}

As áreas incendiadas foram mapeadas utilizando a função de cálculo de área de um receptor de sinal GPS de navegação Garmin ®. Foram feitas visitas de campo em diferentes datas, conforme os incêndios aconteciam, e as áreas incendiadas foram demarcadas percorrendo a poligonal da área. Identificou-se, também, o tipo de vegetação das áreas mapeadas nas mesmas visitas. Grande parte das áreas incendiadas foi mapeada nos meses de outubro e novembro de 2014.

\subsection{Equação universal de perda de solo: determinação dos fatores}

Para a estimativa das perdas de solo nas áreas incendiadas na Bacia do Rio Taquari, utilizou-se a USLE (WISCHMEIER e SMITH, 1965). A USLE é representada pela equação (1):

$$
A=R \cdot K \cdot L \cdot S \cdot C \cdot P
$$

Sendo, A: estimativa da perda de solo por área $\left(\mathrm{t} \cdot \mathrm{ha}^{-1} \cdot \mathrm{ano}^{-1}\right)$; R: fator de erosividade da chuva ou o potencial de erosão causada pela chuva $\left(\mathrm{MJ} \cdot \mathrm{mm} \cdot \mathrm{ha}^{-1} \cdot \mathrm{h}^{-1} \mathrm{ano}^{-1}\right)$; K: fator de erodibilidade do solo que varia de acordo com os tipos de solos $\left(\mathrm{t} \cdot \mathrm{ha} \cdot \mathrm{h} \cdot \mathrm{ha}^{-1} \mathrm{MJ}^{-1} \mathrm{~mm}^{-}\right.$ 1); LS: fator topográfico (adimensional); C: fator do uso e ocupação do solo (adimensional) e $\mathrm{P}$ : medidas conservacionistas e de controle de erosão (adimensional).

$\mathrm{O}$ fator de erosividade (R) foi obtido através dos dados hidrológicos disponibilizados pela Agência Nacional de Águas - ANA. Considerou-se a série histórica dos dados pluviométricos de 24 estações distribuídas pelo Distrito Federal nos anos de 1971 até 2006. Utilizou-se a planilha eletrônica Microsoft Excel e foram considerados apenas os valores de precipitação mensal e anual provenientes de anos que não apresentaram falhas de dados.

Como os dados sistemáticos de pluviosidade, que trazem informações sobre intensidade e duração das precipitações, são escassos, Lombardi Neto (1977) criou uma equação que relaciona média mensal com os valores de energia cinética $(\mathrm{E})$ da chuva e intensidade (I). Esta equação foi avaliada por Galdino (2015) com o objetivo de sua aplicação para o estado de Goiás, Distrito Federal e entorno. Ele determinou coeficientes de correlação linear de Pearson $(r)$ entre as médias mensais de chuva de 88 postos pluviométricos de Goiás, Distrito Federal e entorno e os registros de chuva de Campinas no período de 1954 a 1975 , local para o qual a equação foi desenvolvida. Dessa forma, observou-se que a aplicação da equação para os dados de chuva de Goiás, Distrito Federal e entorno foi considerada satisfatória. A equação é descrita como:

$$
E I_{30 \text { mensal }}=68,7\left(\frac{r^{2}}{P}\right)^{0,85}
$$

Em que: El é a média mensal do índice de erosão em $\mathrm{MJ} \mathrm{mm} \mathrm{ha}^{-1} \mathrm{~h}^{-1}$; $\mathrm{R}$ é a precipitação média mensal, em mm; P é a precipitação, média anual, em mm; 

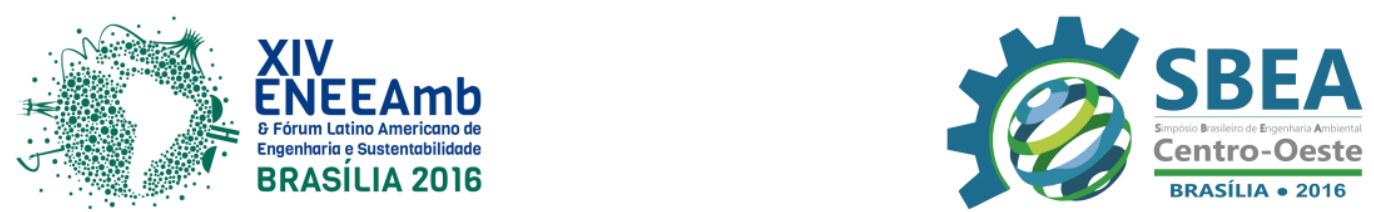

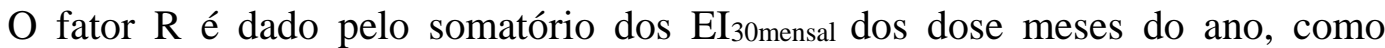
mostra a seguir.

$$
R=\sum_{1}^{12} E I_{30 m e n s a l}
$$

Realocados para ambiente SIG, os resultados da erosividade foram interpolados pelo Método do Inverso do Quadrado da Distância (IDW). De acordo com Costa e Silva (2012), esse método de interpolação global se baseia no princípio de que quanto mais próximo estiver um ponto do outro, maior é a correlação entre seus valores.

$\mathrm{O}$ fator de erodibilidade dos solos $(\mathrm{K})$ foi obtido a partir da associação das unidades pedológicas da área de estudo junto aos dados oferecidos pela Empresa Brasileira de Pesquisa Agropecuária (EMBRAPA, 1978), com os valores de erodibilidade disponíveis na literatura. Wischmeier (1965) descreve os valores de K para o Latossolo Vermelho Escuro como 0,018 t.ha.h (ha.MJ.mm) ${ }^{-1}$, para o Cambissolo como 0,039 t.ha.h (ha.MJ.mm) ${ }^{-1}$ e para o Latossolo Amarelo como 0,028 t.ha.h (ha.MJ.mm) ${ }^{-1}$.

Para a determinação do fator LS, utilizaram-se as curvas de nível, pontos cotados e hidrografia do Distrito Federal, estabelecidas no levantamento com escala de 1:10.000 para todo o território da capital federal. Estes dados foram interpolados no software ArcGIS (® 10.1, criando um modelo digital de elevação da área com resolução espacial de 2 metros.

Primeiramente definiram-se os valores de L para cada pixel através da Equação (4), proposta por Desmet et. al. (1996). Para a aplicação deste algoritmo, requer-se a geração de um mapa de fluxo acumulado e de direção de fluxo. Para cada pixel, calculam-se a declividade, a direção de fluxo e a quantidade de fluxo que se acumulou a montante do pixel.

$$
L_{i, j}=\frac{\left[\left(A_{i, j-i n}+D^{2}\right)^{m+1}-\left(A_{i, j-i n}\right)^{m+1}\right]}{\left[D^{m+2} x_{i, j}{ }^{m}(22,13)^{m}\right]}
$$

Em que $\mathrm{L}_{\mathrm{i}, \mathrm{j}}=$ fator de comprimento de vertente de uma célula com coordenadas $(\mathrm{i}, \mathrm{j}) ; \mathrm{A}_{\mathrm{i}, \mathrm{j}-\mathrm{in}}=$ área de contribuição de uma célula com coordenadas $(\mathrm{i}, \mathrm{j})\left(\mathrm{m}^{2}\right) ; \mathrm{D}=$ tamanho da grade de células $(\mathrm{m}) ; \mathrm{X}_{\mathrm{i}, \mathrm{j}}=$ valor da direção do fluxo; e $\mathrm{M}=$ coeficiente que assume os valores: 0,5 , se $\mathrm{s} \geq 5 \%$ (s é o grau de declividade); 0,4 , se $3 \% \leq \mathrm{s}<3 \%$; e 0,2 , se se $\mathrm{s}<1 \%$.

$\mathrm{O}$ fator $\mathrm{S}$ foi gerado a partir da Equação (5), de acordo com a metodologia proposta por Bertoni e Lombardi Neto (2005). Assim, determinou-se o fator topográfico (LS) pelo produto dos fatores L e S.

$$
S=0,00654 s^{2}+0,0456 s+0,065
$$

Onde: $\mathrm{S}=$ fator de declividade (adimensional); e $\mathrm{s}=$ declividade da vertente $(\%)$.

Para o fator de uso do solo (C) para o Cerrado, de acordo com EMBRAPA (2003), adota-se 0,140. Dessa forma, adotou-se esse valor para o cenário 1, onde a vegetação predominante encontrada é de Cerrado.

De acordo com Pimenta (2000), no caso de solo desprotegido (corte raso ou fogo), o valor para o fator $\mathrm{C}$ deverá ser de 0,5 , independente da espécie florestal presente. Nesse trabalho, a autora definiu os valores do fator $C$ para o cálculo de erosão hídrica utilizando a USLE. Dessa forma, adotou-se este valor para o cenário 2.

Em relação ao fator de medidas conservacionistas do solo (P), adotou-se o valor 1; pois, segundo Corrêa (2009), este é o valor adotado quando não há qualquer prática de controle de erosão no local. Adotou-se o pior cenário quanto a este fator para enfatizar a importância das áreas incendiadas quando se trata de perda de solo. 

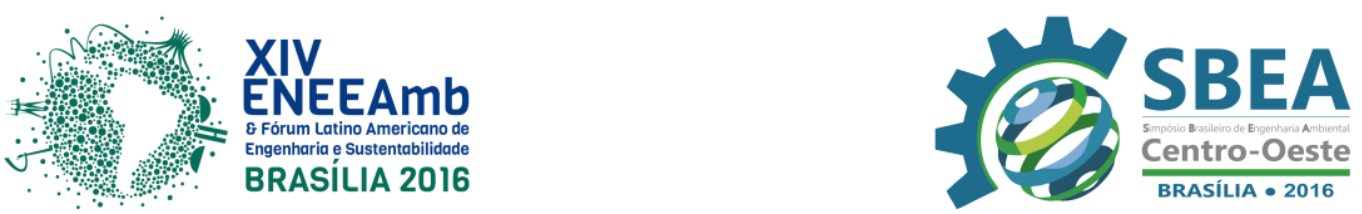

\section{RESULTADOS E DISCUSSÕES}

Os incêndios florestais aconteceram no ano de 2014, no período de setembro a dezembro, distribuídos em sete eventos diferentes em que a vegetação foi extremamente afetada. Aproximadamente 2,25 $\mathrm{km}^{2}$ foram queimados, o que corresponde a aproximadamente $41 \%$ da bacia. A Figura 1 mostra, além da localização, a distribuição das áreas queimadas na bacia.

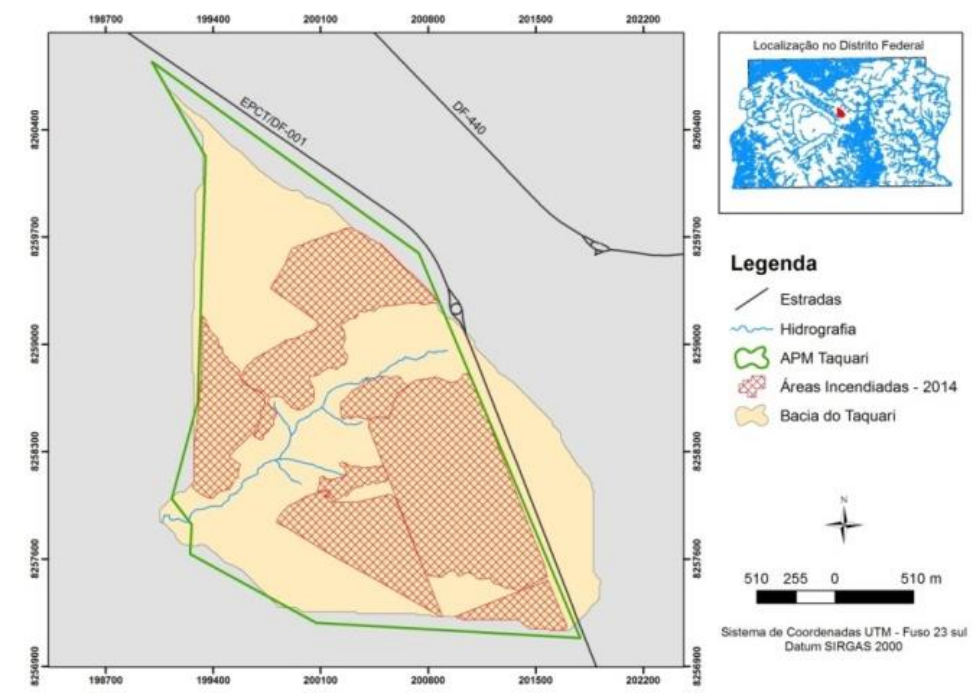

Figura 1: Localização e distribuição das áreas queimadas na bacia do Taquari.

As precipitações não se distribuem uniformemente durando o período anual. Segundo levantamento de dados disponibilizados pela ANA, nas estações pluviométricas do Distrito Federal, as maiores precipitações ocorrem entre outubro e março, e consequentemente, os maiores potenciais de erosividade da chuva são encontrados nesse período (Silva et al., 2015). Porém, ainda analisando os dados históricos de pluviosidade do Distrito Federal, os maiores potenciais de erosividade se encontram nos três primeiros meses do referido período, o que tem maior implicação no que tange aos efeitos erosivos pós incêndio florestal, uma vez que o Cerrado ainda não se recuperou dos eventos de queimada ocorridos poucos meses antes às precipitações com maior potencial erosivo. Os valores encontrados para o fator R na bacia são apresentados pela Figura 2. O valor médio encontrado foi de $8540,82 \mathrm{MJ} \mathrm{mm} \mathrm{ha}^{-1} \mathrm{~h}^{-1}$.

Foram identificados três tipos de solo na bacia: Latossolo Vermelho Escuro, Cambissolo e Latossolo Amarelo. Os valores de $\mathrm{K}$ variam entre 0,018 e 0,039 t.ha.h (ha.MJ.mm) ${ }^{-1}$. Esses dados foram incorporados ao mapa de pedologia da área para a realização do cálculo da USLE, como mostra a Figura 3. 


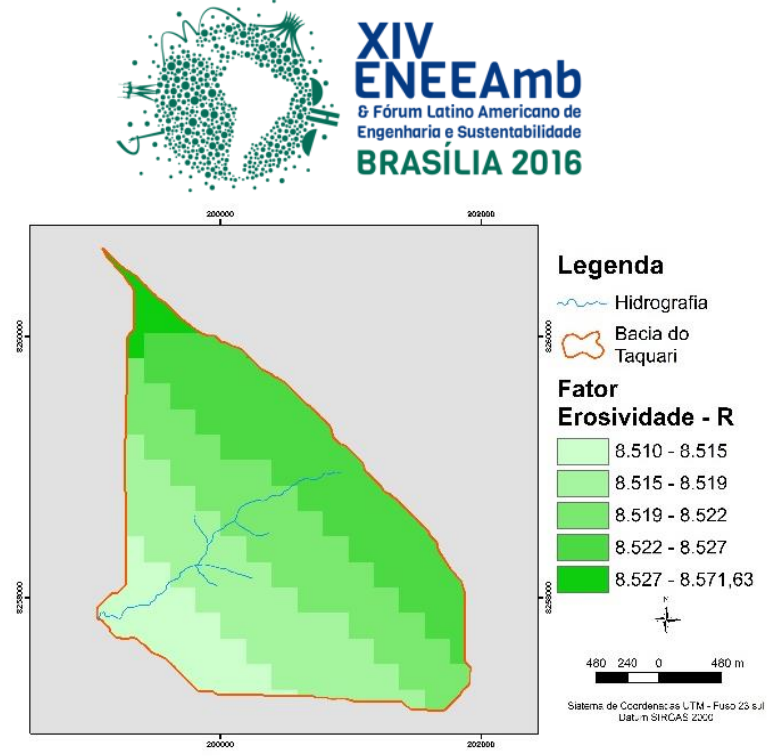

Figura 2: Fator R para as chuvas ocorridas na bacia do Taquari.

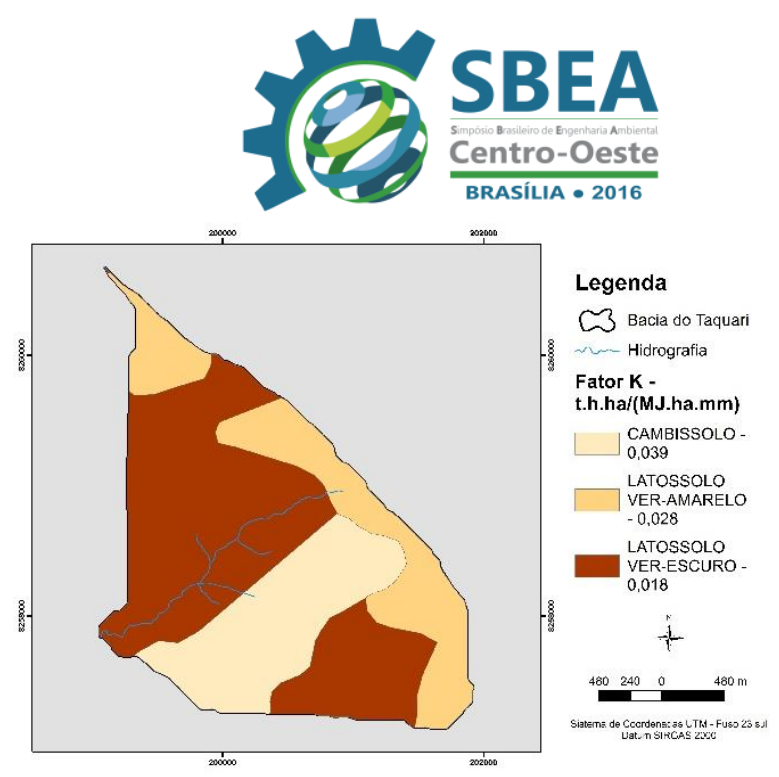

Figura 3: Fator K para os solos encontrados na bacia do Taquari.

Em relação ao fator topográfico LS, encontrou-se, em grande parte, valores que variam de 0,004 a 15, chegando a valores próximos aos 50 em algumas pequenas áreas mais próximas ao córrego. A Figura 4 mostra a distribuição e valores de LS para toda a bacia do Taquari.

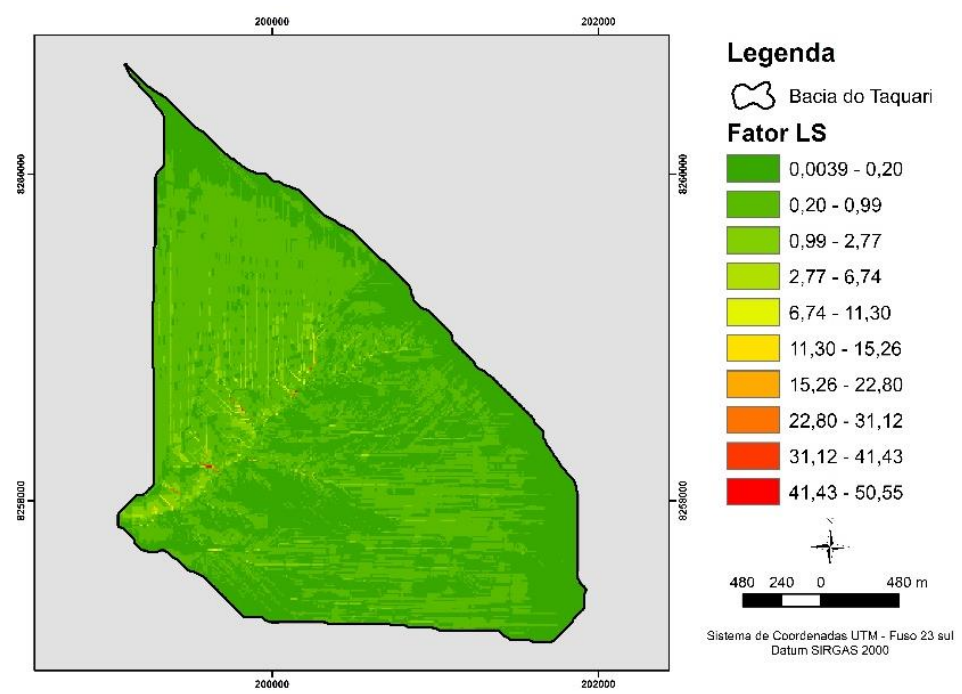

Figura 4: Fator LS encontrado na bacia do Taquari

Como era de se esperar, o estudo mostrou que a ocorrência de eventos de queimada na bacia do Rio Taquari implicou em maior estimativa de perda de solo. No cenário 1, as perdas ficaram entre os valores de 0,27 e $884,70 \mathrm{t}(\text { ha·ano })^{-1}$, como mostra a Figura 5. Já no cenário 2, as perdas ficaram entre os valores de 0,97 e $3159 \mathrm{t}$ (ha·ano $)^{-1}$, como mostra a Figura 6. A estimativa de perda de solo para o cenário 2 aumentou em $257 \%$ dos valores do cenário 1. 


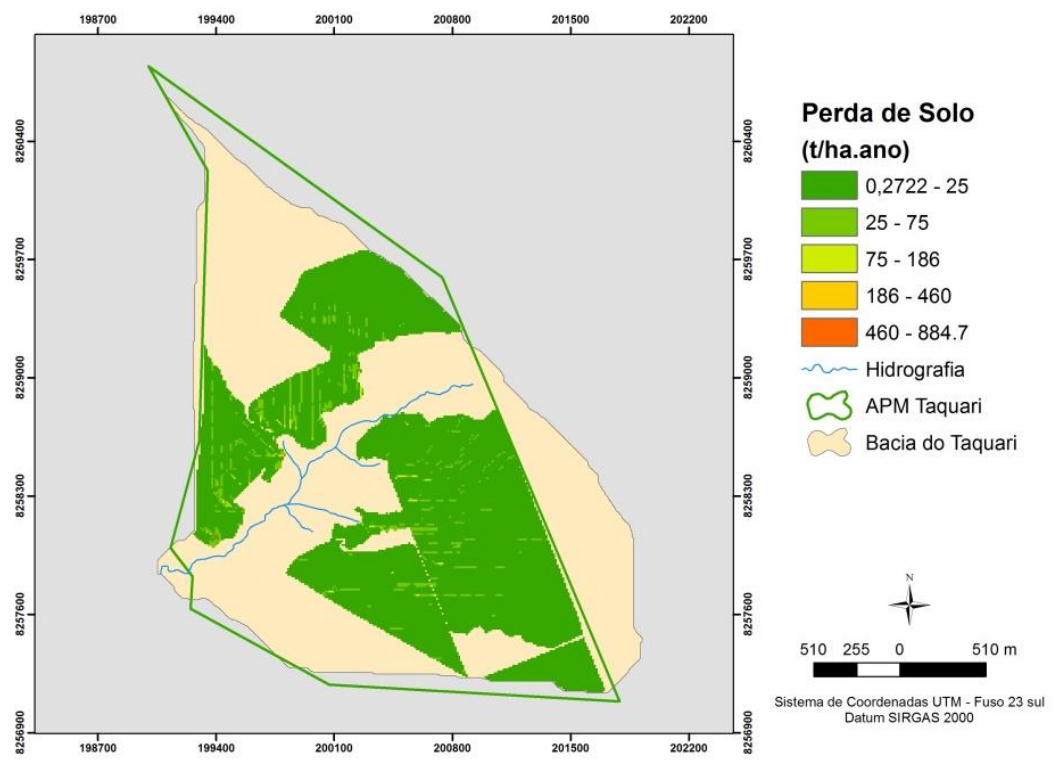

Figura 5: Perda de solo no cenário 1: anterior aos eventos de queimada.

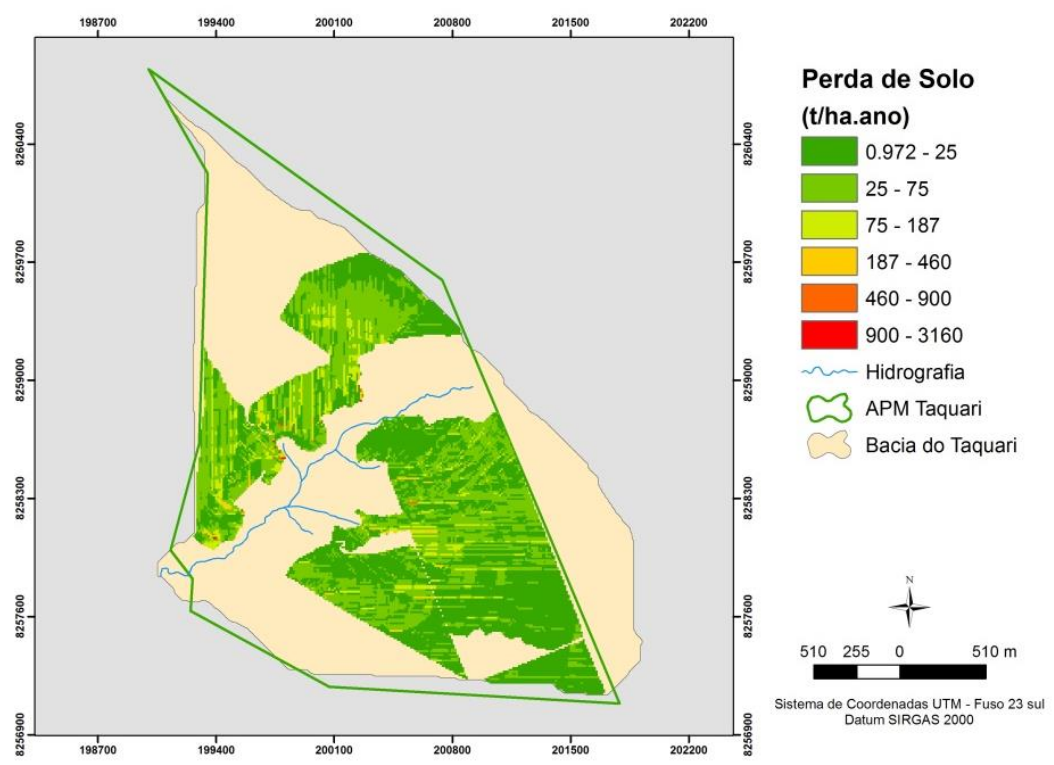

Figura 6: Perda de solo no cenário 2: pós eventos de queimada.

\section{CONCLUSÕES E RECOMENDAÇÕES}

Áreas incendiadas potencializam os processos erosivos, uma vez que, após eventos de queimada, os solos ficam expostos e mais susceptíveis aos fatores que causam perdas de solo em vertentes. Trazendo para a aplicação da USLE, o fator de cobertura de solo ganha proporções importantes quando alterado pelos eventos de queimada, implicando em maiores resultados finais da equação.

Conclui-se com o estudo que as áreas incendiadas na bacia do Rio Taquari resultaram em maior potencial erosivo, uma vez que a cobertura do solo tem fundamental importância na sua proteção contra esses processos. Diante desse pressuposto, é importante a conscientização da importância das áreas queimadas nas perdas de solo por erosão hídrica. Este fator tem influenciado os serviços ambientais oferecidos para humanidade e colaborado 

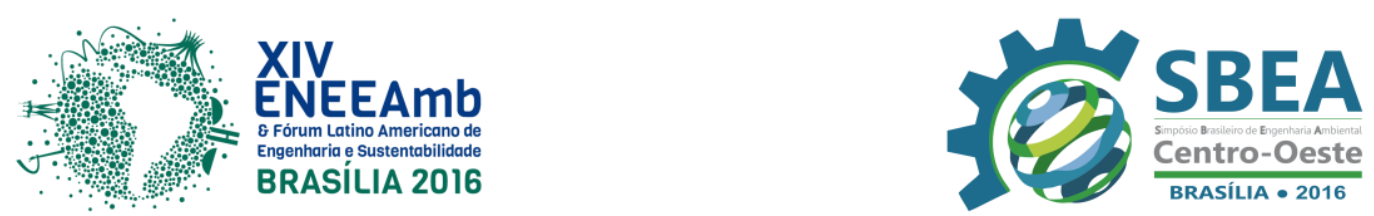

para a degradação de ecossistemas. Portanto, práticas para a prevenção de incêndios florestais devem ser tomadas para que essas áreas não sofram com o processo de degradação por erosão amplificados por esses eventos. Além disso, é importante pensar sobre práticas conservacionistas do solo em áreas que repetidas vezes sofrem com incêndios florestais.

\section{REFERÊNCIAS E CITAÇÕES}

BERTONI, J.; LOMBARDI NETO, F. Conservação do Solo. $5^{\mathrm{a}}$ ed. São Paulo: Ícone, 2005. CAESB - Companhia de Saneamento Ambiental do Distrito Federal. Relatório da Qualidade da Água Distribuída pela Caesb em 2011. Edição: Março de 2012.

CORRÊA, R. S. Recuperação de áreas degradadas pela mineração no Cerrado: Manual para revegetação. $2^{a}$ edição. Universidade Católica de Brasília. Brasília, Editora Universa. p. 4446, 2009.

COSTA, S.G.F.; SILVA, R.M. Potencial natural e antrópico de erosão na bacia experimental do Riacho Guaraíra. Cadernos do Logepa, 7(1): 72-91, 2012.

DESMET, P. J. J. et. al. A GIS procedure for automatically calculating the USLE LS factor on topographically complex landscape units. Journal of Soil and Water Conservation, 51 (5): 427-433. 1996.

EMBRAPA - Empresa Brasileira de Pesquisa Agropecuária. Mapa de reconhecimento dos solos do DF-1978-embrapa-1:100.000. Centro Nacional de Pesquisas do Solo. Rio de Janeiro: Embrapa Solos, 1978

EMBRAPA - Empresa Brasileira de Pesquisa Agropecuária. Perdas de Solo na Bacia do Alto Taquari. Boletim de Pesquisa e Desenvolvimento. Rio de Janeiro: Dezembro, 2003.

GALDINO, Sérgio. Distribuição espacial da erosividade da chuva no Estado de Goiás e no Distrito Federal. Boletim de Pesquisa e Desenvolvimento. Empresa Brasileira de Pesquisa Agropecuária. Embrapa Monitoramento por Satélite. São Paulo: Campinas, 2015.

HERNANI, L. C., et. al. A erosão e seu impacto. Uso agrícola dos solos brasileiros. Rio de Janeiro: Embrapa Solos, 2002. p. 47-60.

LOMBARDI NETO, F. Rainfall erosivity - its distribution and relationship with soil loss as Campinas, Brasil. West Lafayette, 1977. 53p. Dissertação (Mestrado) - Purdue University.

LOURENÇO, L. Evolução de vertentes e erosão dos solos, nas serras de xisto do centro de Portugal, em consequência de incêndios florestais. Análise de casos observados em 1987. Relatório Técnico 8805, Centro de Mecânica dos Fluidos, Coimbra, Portugal. 1988

PIMENTA, M. T. Directrizes para a aplicação da Equação Universal de Perda dos Solos em SIG, fator de cultura C e Fator de Erodibilidade do Solo K. Direção de Seviços dos Recursos Hídricos - INAG. Lisboa, Portugal, 2000.

SILVA, Thales Thiago Sousa et al. Caracterização ambiental da bacia do Ribeirão das Pedras: entendendo a dinâmica ambiental local. In XXI Simpósio Brasileira de Recursos Hídricos, Brasília, 2015.

WISCHMEIER, W. H., and Smith, D. D. Predicting rainfall-erosion losses from cropland east of the Rocky Mountains. Agr. Handbook No. 282, U.S. Dept. Agr., Washington, 1965.

ZEE - Zoneamento Ecológico Econômico do Distrito Federal. Brasília, 2012. 